\title{
NeuroAIDS: An Evolving Epidemic
}

\author{
Christopher Power, Lysa Boissé, Sean Rourke, M. John Gill
}

\begin{abstract}
Over 60,000 Canadians are infected with human immunodeficiency virus (HIV). Greater than 50\% of these individuals will develop a neurological disorder despite the availability of highly active antiretroviral therapy. HIV causes nervous system disease at all stages of infection with adverse effects on quality of life, adherence to medications, employment and survival. These disorders include opportunistic infections in addition to distinct HIV-associated neurological syndromes and undesirable treatment-related effects. The latter two groups of disorders are often undiagnosed and untreated in both adolescents and adults. Direct HIV infection of central nervous system causes HIV-associated dementia, which is a progressive subcortical dementia. HIV infection of the peripheral nervous system produces a painful sensory neuropathy termed distal sensory polyneuropathy, which may be exacerbated by several antiretroviral drugs. Other important HIV-induced neurological disorders include vacuolar myelopathy and an increased risk of seizures. Future issues that will confound the presentation and treatment of HIV-induced nervous system disorders include the increasing prevalence of drugresistant HIV strains, increasing age of HIV-infected patients, hepatitis C virus co-infection and the Immune Reconstitution Inflammatory Syndrome. Herein, we review the clinical presentations, underlying pathogenesis and treatments of this burgeoning group of neurological disorders.
\end{abstract}

RÉSUMÉ: Le SIDA neurologique : une épidémie en évolution. Plus de 60,000 Canadiens sont infectés par le virus de l'immunodéficience humaine (VIH). Plus de 50\% d'entre eux présenteront un trouble neurologique malgré la disponibilité de la thérapie antirétrovirale hautement active. Le VIH cause une maladie du système nerveux à tous les stades de l'infection et entraîne des effets délétères sur la qualité de vie, la fidélité à la médication, l'emploi et la survie. Parmi les maladies du système nerveux on doit mentionner les infections opportunistes en plus des syndromes neurologique propres à l'infection par le VIH et des effets indésirables du traitement. Ces deux derniers groupes de problèmes sont souvent non diagnostiqués et non traités, tant chez les adolescents que chez les adultes. L'infection directe du système nerveux central par le VIH cause une démence associée au VIH qui est une démence sous-corticale progressive. L'infection du système nerveux périphérique par le VIH entraîne une neuropathie sensitive douloureuse appelée polyneuropathie sensitive distale qui peut être exacerbée par plusieurs médicaments antirétroviraux. La myélopathie vacuolaire et une augmentation du risque de convulsions sont également des problèmes neurologique importants dus VIH. À l'avenir, la prévalence croissante de souches du VIH qui sont résistantes aux médicaments, des patients infectés par le VIH qui vieillissent, la co-infection par le virus de l'hépatite C et le syndrome inflammatoire de restauration immunitaire seront des facteurs de confusion dans le tableau clinique et le traitement des troubles du système nerveux provoqués par le VIH. Nous revoyons dans cet article le tableau clinique, la pathogenèse sous-jacente et le traitement de ce groupe de troubles neurologique en pleine éclosion.

Can. J. Neurol. Sci. 2009; 36: 285-295

Nervous system disorders caused by human immunodeficiency virus (HIV) infection involve the central or peripheral nervous systems in over $50 \%$ of infected individuals at some point during the course of infection ${ }^{1}$. Most disorders of the nervous system become clinically evident with advancing immunosuppression during the acquired immuno-deficiency syndrome (AIDS) phase of disease (Table 1). Almost 65 million people globally have been infected with the HIV since it was first identified in the early 1980's. In Canada over 60,000 persons are estimated to be infected with HIV, principally HIV1. The HIV-1 B clade is the predominant HIV-1 subtype causing infection in the industrialized world and hence, the disorders discussed herein are those most thoroughly described for HIV-1 $\mathrm{B}$ infections. Within Canada, groups at high or increasing risk for
HIV infection include men having sex with men, injection drug users, Aboriginal peoples, women, youth, inmates and peoples from endemic regions such as sub-Sahara Africa. With the

From the Departments of Medicine, Medical Microbiology and Immunology, Psychiatry, University of Alberta (CP), Edmonton; Departments of Medicine, Microbiology and Infectious Diseases, University of Calgary (MJG), Calgary, AB; Department of Medicine, Queen's University (LB), Kingston; Department of

Psychiatry, University of Toronto (SR), St. Michael's Hospital, Toronto, ON, Canada. Received October 17, 2008. Final Revisions Submitted January 19, 2009. Correspondence to: Christopher Power, Department of Medicine (Neurology), 6-11 Heritage Medical Research Centre, University of Alberta, Edmonton, Alberta, T6G 2S2, Canada. 
advent of highly active antiretroviral therapy in the mid-1990's, many HIV-1 seropositive individuals in industrialized countries now live upwards of 20 years after initial infection, long after they have developed $\operatorname{AIDS}^{2,3}$. Given the rising prevalence of HIV infection globally including Canada, there is a high likelihood of practicing physicians encountering patients with HIV infection and often with a neuropsychiatric disorder.

There are two major groups of nervous system disorders frequently encountered during HIV-1 infection including opportunistic infections and primary neurological disorders. Opportunistic infections of the central and peripheral nervous systems arise as consequences of HIV-induced immunosuppression and consist of Toxoplasmic encephalitis, Cryptococcal meningitis, Progressive Multifocal Leukoencephalopathy, primary central nervous system lymphoma, central nervous system tuberculosis, cytomegalovirus encephalitis and radiculitis, or multidermatomal herpes zoster (Table 1) (reviewed $i^{4,5}$ ). These conditions are rarely seen in patients in ongoing care and receiving highly active antiretroviral therapy. The neurological syndromes, assumed to be caused directly by HIV-1 infection, have emerged as the more common nervous system disorders in industrialized countries' clinics. These latter disorders are often subtle and are frequently under-recognized because concurrent illnesses or drug-related effects. Despite the availability of highly active antiretroviral therapy, HIV-related neurological disorders continue to represent substantial personal, economic and societal burdens with worsened quality of life, employability, survival and are often complicated by mental health issues ${ }^{6}$. This review examines the principal neurological disorders associated with HIV infection including their diagnosis and treatment based on review of the literature using key words (HIV, dementia, neuropathy, seizure, antiretroviral therapy) for searching electronic and print databases, together with our collective clinical experience. Like many areas in medicine, particularly neurology and psychiatry, the diagnosis of the disorders reviewed in this manuscript is largely predicated on syndromic recognition and not definitive or quantitative diagnostic tests although the long term goal is to establish evidence-based and widely applicable tools for diagnosis. We also use the descriptor, neuropsychiatric, because there is often overlap of all of the disorders discussed herein with mental health issues including affective disorders or addiction, which shape the disease phenotype in terms of presentation and response to treatment(s).

\section{HIV neurological disorders}

This group of syndromes reflects HIV-1's immediate and deleterious effects on neural cells, causing damage to the brain, spinal cord, and peripheral nerves in adults and adolescents. The most common of these primary HIV-associated neuropsychiatric illnesses include HIV-associated dementia (also termed AIDS Dementia Complex or HIV encephalopathy) and distal sensory polyneuropathy, which is frequently exacerbated by antiretroviral drug toxicity ${ }^{7}$. Other central and peripheral nervous system disorders complicate the course of HIV-1 infection including seizures, myelopathy, aseptic meningitis, multiple neuropathies and myopathies (Table 2). The estimated overall prevalence of nervous system disorders among patients receiving highly active antiretroviral therapy but also requiring neurological care is over 25\% (Power and Gill, unpublished) although autopsy studies suggest upwards of $90 \%$ of HIV/AIDS patients exhibit neuropathological changes ${ }^{8}$. Unfortunately, the incidence and prevalence of HIV-related nervous system disorders is not established in Canada, although data from our clinics indicate that the prevalence of neurological disease is high (peripheral neuropathy, 41\%; neurocognitive impairment, $25 \%$ seizure/epilepsy, 20.7\%; CNS opportunistic infections, $14.7 \%$ ) (Power and Gill, unpublished). The individual neurological syndrome can often be predicted in the context of the CD4+ T lymphocyte level in blood (Figure 1) or by estimating the time from original infection (Figure 2). For example, HIV-associated dementia and distal sensory polyneuropathy are typically features of AIDS, while antiretroviral toxic neuropathy and a less severe neurocognitive disorder termed Minor Neurocognitive Disorder, frequently antecedent to HIV-associated dementia, may present earlier in the disease course at higher CD4+ T cell levels in blood. Human immunodeficiency virus-associated dementia and Minor Neurocognitive Disorder have been termed collectively as HIVassociated Neurocognitive Disorder ${ }^{9}$.

\section{Clinical Case}

A 38-year-old homosexual Caucasian male accountant was referred to an HIV care clinic with a recent diagnosis of HIV/AIDS based on HIV-1 positive serology, reduced CD4 ${ }^{+} \mathrm{T}$ cell count $(150$ cells $/ \mu \mathrm{L})$ and a concurrent diagnosis of Pneumocystis jiroveci pneumonia. In the course of evaluation for potential highly active antiretroviral therapy, it became evident from the patient and his family that he was progressively more forgetful, confused intermittently, agitated but also displayed psychomotor slowing. His work performance had substantially deteriorated over the preceding three months. There was no history of drug abuse or familial cognitive impairment. Physical exam disclosed a masked face, interrupted saccadic eye movements, plastic rigidity in all limbs, a stooped shuffling gait, hypereflexia, including a brisk jaw jerk. The HIV Dementia Scale score was 8/16 while the Folstein Mini-Mental State Examination score was 27/30. Neuropsychological testing revealed impaired performance on Symbol-Digit, Trail Making A and B and Grooved Pegboard testing (greater than two standard deviations below the age-adjusted mean for all tests). A brain magnetic resonance image revealed cerebral cortical atrophy on T1-weighted image (Figure 3A) with increased diffuse white matter signal in periventricular regions, on T2-weighted (Figure 3B) and FLAIR (Figure 3C) images. Cerebrospinal fluid analysis disclosed increased protein $(0.8 \mathrm{~g} / \mathrm{L})$, normal glucose $(4.0$ $\mathrm{mmol} / \mathrm{L})$ with a pleocytosis $\left(14 \times 10^{6} / \mathrm{L}\right.$ cells; $90 \%$ lymphocytes $)$ and no other pathogens (tuberculosis, cryptococcus, varicella zoster virus, herpes simplex-1, enteroviruses, JC virus) were detected by PCR or on microscopy. Other investigations of blood (thyroid stimulating hormone, vitamin B12, VDRL test, renal and hepatic parameters) were unremarkable. The plasma viral load was $10^{5}$ copies $/ \mathrm{ml}$ while the cerebrospinal fluid viral load was $10^{4}$ copies $/ \mathrm{ml}$. The patient was diagnosed with HIVassociated dementia based on clinical presentation, physical examination, neuroimaging, cerebrospinal fluid and blood tests, and neuropsychological assessment. Highly active antiretroviral therapy was started including zidovudine, lamivudine and 
ritonavir-lopinavir. In addition, the patient and his family were provided with in-home assistance as he was unable to care for himself and his personal matters through social work and occupational therapy. Three months later, the patient was reassessed in the clinic and found to be living semiindependently requiring only limited support from family and the community. However, he had developed painful feet at night with allodynia, reduced vibratory and temperature sensation in the feet and absent deep tendon reflexes in the ankles. He had no systemic risk factors (diabetes, hepatitis $\mathrm{B}$ and $\mathrm{C}$ virus infections, hypothyroidism, syphilis) for peripheral neuropathy except for HIV infection. He was diagnosed with distal sensory polyneuropathy based on clinical findings and nerve conduction studies showing an axonal neuropathy. The patient was treated with gabapentin $300 \mathrm{mg}$ three times per day and his pain subsided. Within six months the patient was living independently and was considering a return to work on a part-time basis (See Question and Answer Section).

\section{HIV neuropathogenesis}

The pathobiology of primary HIV-related neuroplogical disorders is defined by both neuroinflammation and neuronal injury (Figure 4) (reviewed in ${ }^{10}$ ). Human immunodeficiency virus invades the central and peripheral nervous systems soon after initial infection through HIV-infected mononuclear cells (macrophages and $\mathrm{CD}^{+} \mathrm{T}$ cells) traversing the blood-brain or -

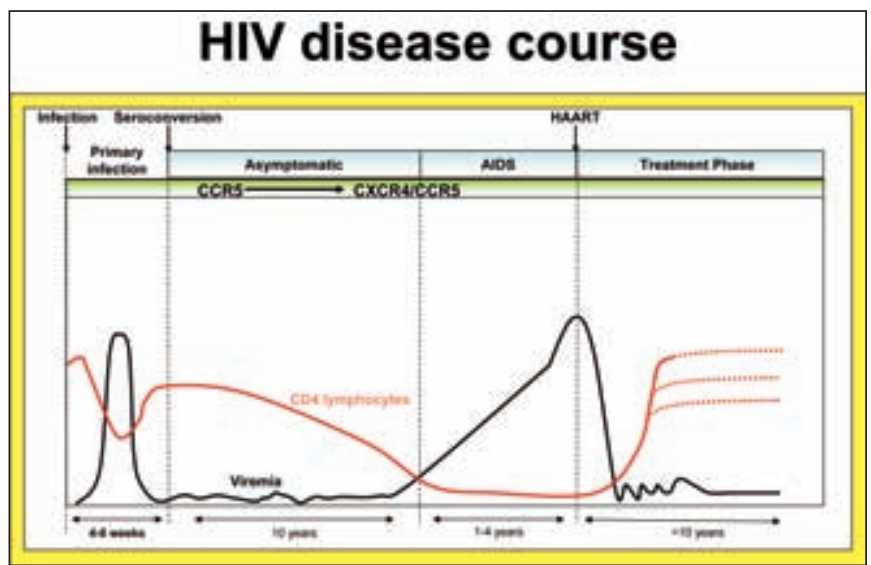

Figure 1: Natural history of untreated HIV infection and response to treatment. In the first 4-8 weeks after infection, there is a dramatic rise in viral load accompanied by a decrease in $\mathrm{CD}^{+} \mathrm{T}$ cell levels in blood after seroconversion. During the asymptomatic period of infection, viral load remains relatively low. An increase in viral load after approximately 10 years of infection is associated with progression to AIDS. CD4 $4^{+} T$ lymphocytes drop abruptly after initial infection only to rise again but their levels decline slowly over the course of infection. During the course of HIV infection, there is a progressive change in viral co-receptor preference from CCR5 to CXCR4. The initiation of highly active antiretroviral therapy (HAART), preferably before patients become severely immune suppressed, reduces the viral load in the blood and results in a variable increase in the $C D 4^{+} T$ cell level depending on the individual patient and antiretroviral regimen (adapted from ${ }^{16}$ ). nerve barriers (neuroinvasion) with ensuing tissue infiltration. Within the nervous system, HIV subsequently infects resident microglia, perivascular macrophages and astrocytes but not neurons or oligodendrocytes (neurotropism). Infection of cells in the nervous system is largely mediated by CD4 and the chemokine receptor, CCR5, serving as viral receptors. The development of nervous system disease (neurovirulence) occurs through two non-cell autonomous mechanisms including cytotoxic effects of (a) HIV-encoded proteins (gp120, Vpr and Tat) or (b) host molecules (cytokines, chemokines, eicosanoids, free radicals, proteases). These viral and host molecules are secreted by activated or infected microglia/macrophages. Chronic exposure of neurons, astrocytes or Schwann cells to these secreted molecules culminates in neuronal process retraction (synaptic injury or peripheral nerve) and eventual cell death (Figure 4). While neuronal apoptosis has garnered substantial attention in the literature, it is becoming apparent that other types of programmed cell death (autophagy) and necrosis likely contribute to reduced neural cell viability and survival ${ }^{10}$.

The neuropathological hallmarks of advanced HIV infection of the central nervous system include HIV encephalitis defined by multinucleated giant cells, perivascular cuffs, comprised of macrophages and lymphocytes, diffuse white matter pallor, viral antigen detection with ensuing neuronal or synapto-dendritic loss, which are often present and are correlated with magnetic resonance imaging and spectroscopy findings ${ }^{11-13}$. In the peripheral nervous system, damage to neuronal soma in the

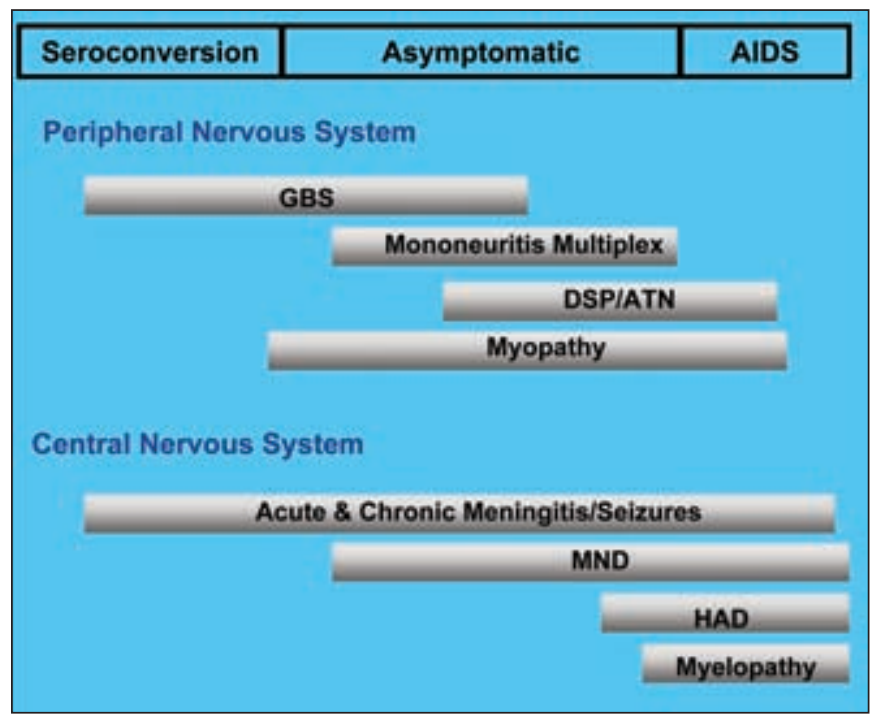

Figure 2: Primary HIV-induced neuroplogical syndromes occurring during the course of infection. All levels of the nervous system can be affected by HIV. Individual syndromes arise depending on the degree of immune suppression, i.e.; acute aseptic meningitis, Guillain-Barré Syndrome (GBS), antiretroviral toxic neuropathy (ATN) and Minor Neurocognitive Disorder (MND), tend to arise earlier in the disease course, while HIV-associated dementia (HAD) and distal sensory polyneuropathy (DSP) develop later with increasing immunosuppression (adapted from $^{7}$ ). 
dorsal root ganglion and a dying back pattern of axonal injury is apparent, particularly in small diameter myelinated and unmyelinated sensory axons, together with infiltrating leukocytes (macrophages and lymphocytes ${ }^{14,15}$. While HIV-1 genome and protein can be detected in both the central and peripheral nervous systems, viral abundance in nervous system tissue in terms of viral RNA, DNA or protein does not seem to be predictive of the diagnoses of HIV-associated dementia or distal sensory neuropathy. There is compelling evidence from models of HIV infection including simian and feline immunodeficiency virus infections that individual viral strains and the sequences of specific viral genes contribute to neuropathogenesis (reviewed in ${ }^{16}$ ). While HIV-1 neuroinvasion and neurotropism occurs in all HIV-infected persons, clinically evident disease or neurovirulence affects only a subset of HIVinfected patients, likely due to specific susceptibility variables (neurosusceptibility), outlined for each disorder in the following sections.

\section{Central nervous system disorders of HIV-1 infection}

\section{HIV-associated dementia}

The development of HIV-associated dementia is among the most devastating consequences of HIV-1 infection because of its unique and progressive clinical manifestations. Human immunodeficiency virus-associated dementia is an AIDS-defining illness (Table 1) and approximately 15-30\% of untreated AIDS patients acquire the diagnosis. Conversely, in populations receiving highly active antiretroviral therapy, the current estimated prevalence of $\mathrm{HIV}$-associated dementia is $10 \%$ with an incidence of $1 \%{ }^{17}$.

\section{Clinical features}

This syndrome is characterized by a clinical triad including neurocognitive impairments (forgetfulness, poor concentration and comprehension, slowed mental processing), emotional disturbances (agitation, apathy), and motor dysfunctions (tremor, bradykinesia, ataxia and spasticity) (Table 3). These signs and symptoms become manifest over weeks to months. Both patients and caregivers are aware of the deterioration in neurological performance and their concerns should be heeded closely (See clinical case). However, HIV-associated dementia displays diversity in its clinical phenotype, including movement disorders $^{18-20}$ and occasionally mania or psychosis ${ }^{21,22}$. Symptoms typically begin once an individual's CD4+ T cell counts drop below 200 cells/ $\mu$ l of blood although with the advent of highly active antiretroviral therapy, HIV-associated dementia is now presenting at higher $\mathrm{CD}^{+} \mathrm{T}$ cell levels. In a large part, the earlier onset of HIV-associated dementia is likely due to limited CNS penetrance by antiretroviral drugs, allowing the virus to replicate in a protected reservoir. The course of HIV-associated dementia is highly variable from patient to patient, and can present as an abrupt decline over a few weeks or a protracted course over several months ${ }^{23}$. Clinical risk factors for HIVassociated dementia include low $\mathrm{CD}^{+} \mathrm{T}$ cell levels, high viral set point early in the infection course, increased viral load in cerebrospinal fluid (CSF), anemia, extremes of age, low bodymass index, injection drug use, both host and viral genetic polymorphisms and possibly female gender and concurrent hepatitis $\mathrm{C}$ virus infection ${ }^{1,24}$.

The estimated prevalence of Minor Neurocognitive Disorder, which may precede HIV-associated dementia, is $20-30 \%$ of all HIV-infected patients and may be complicated by co-morbidities including chronic substance abuse, affective disorders previous
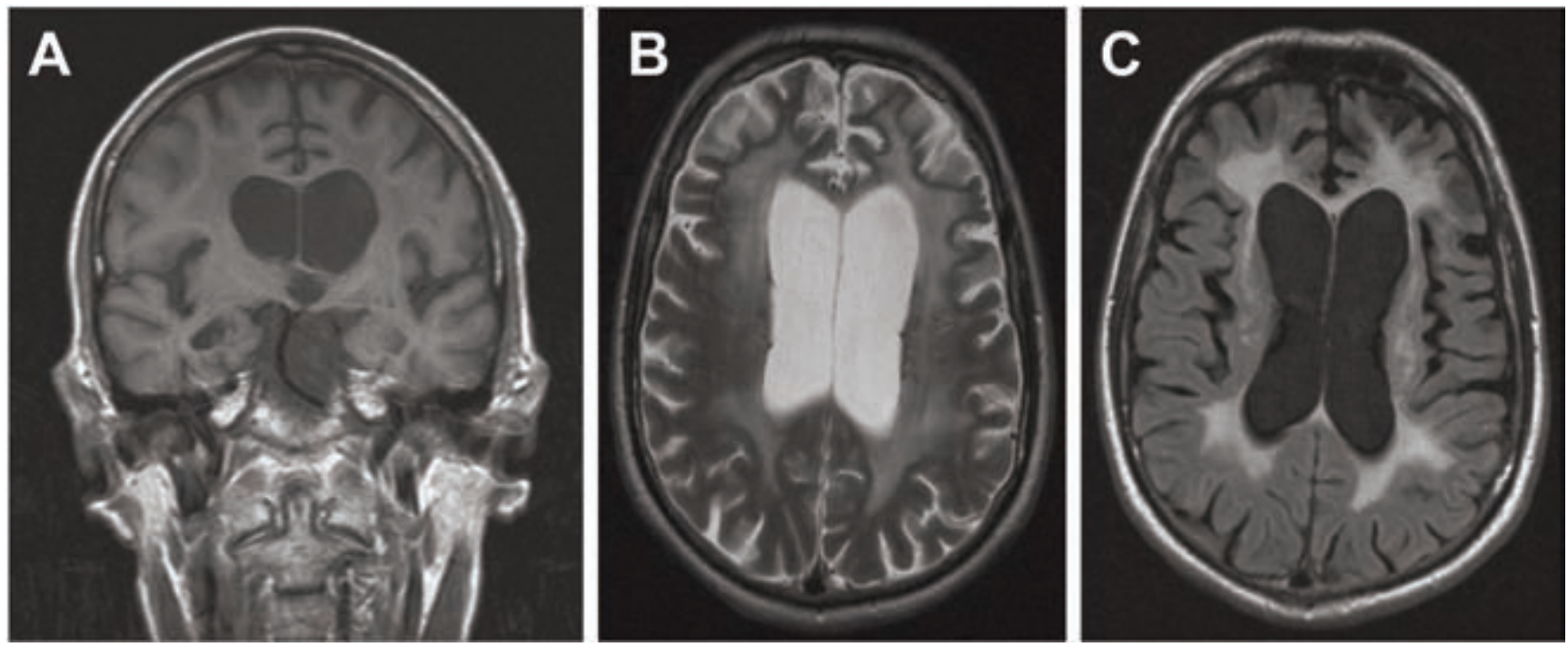

Figure 3: Cranial magnetic resonance imaging of a 38-year-old HIV-1 seropositive male with HIV-associated dementia. (A) T1-weighted image shows hydrocephalus due to central atrophy accompanied by cortical atrophy. (B) T2-weighted image shows enlarged ventricles with increased diffuse white matter signal. (C) FLAIR image exhibits extensive white matter changes with cortical atrophy. 
injury or prior opportunistic infection of the central nervous system. Minor Neurocognitive Disorder presents with the clinical hallmarks of HIV-associated dementia ${ }^{25,26}$, albeit with less severe signs and symptoms and at higher $\mathrm{CD}^{+} \mathrm{T}$ cell levels ${ }^{27}$. Indeed, many patients display features of Minor Neurocognitive Disorder that are unrecognized, especially among patients receiving highly active antiretroviral therapy and are apparently virologically 'suppressed' based on undetectable virus in plasma. Again, these less intrusive neuropsychiatric signs and symptoms require attention as they can contribute to an individual's inability to function effectively in the workplace and at home 28,29 . The diagnoses of HIV-associated dementia or Minor Neurocognitive Disorder herald a worsened survival prognosis, even in the era of highly active antiretroviral therapy ${ }^{30,31}$. The presence of neurocognitive impairment also adversely affects adherence to medications ${ }^{32,33}$, which may underlie the worsened survival among these patients.

\section{Diagnosis}

Radiological features accompanying HIV-associated dementia include cerebral and basal ganglia atrophy and diffuse periventricular white matter hyperintensities on magnetic resonance imaging T2 weighted images (Figure 4) ${ }^{34,35}$, although non-demented HIV/AIDS patients may display less severe but similar radiological changes ${ }^{36}$. Magnetic resonance spectroscopy shows diminished $\mathrm{N}$-acetyl-aspartate levels, a neuronal metabolite ${ }^{37}$ together with increased choline levels indicative of inflammation ${ }^{38}$. Positron emission tomography reveals variable findings in $\mathrm{HIV}$-associated dementia although basal ganglia hypometabolism is a late-stage common feature ${ }^{39}$. Other valuable investigations include cerebrospinal fluid analyses to exclude opportunistic infections; high protein and IgG levels with an accompanying pleocytosis are found in cerebrospinal fluid of $66 \%$ of HIV-associated dementia patients. cerebrospinal fluid HIV-1 copy number together with markers of immune dysregulation (neopterin, $\beta$-2-microtubulin, chemokines) are associated with the presence of HIV-associated dementia but remain uncertain diagnostic markers ${ }^{1}$.

Neuropsychological assessment is a valuable tool in confirming the diagnosis of HIV-associated dementia and also evaluating the response to therapy. Given that HIV preferentially infects and affects the basal ganglia and deep white matter, HIVassociated dementia predictably displays the cardinal features of a "sub-cortical dementia". Hence, HIV-associated dementia is not readily detected by the Folstein Mini-Mental Status Exam unless the patient is severely demented ${ }^{40}$. More useful screening tools for HIV-associated dementia include the HIV Dementia Scale with a sensitivity and specificity exceeding $80 \%{ }^{41}$ and derivatives thereof ${ }^{42}$, the Mental Alteration Test ${ }^{43}$, the Executive Interview $^{44}$, and the HIV Dementia Assessment ${ }^{45}$. The Memorial Sloan-Kettering Scale is a widely accepted tool for monitoring the progression and disability of dementia over time ${ }^{46}$. A more detailed neuropsychological evaluation is often imperative (Symbol-Digit, Grooved Pegboard, Trail Making A and B) in circumstances of co-morbidities (prior head injury, drug abuse) but requires experienced interpretation. It is important to consider that the presence of marked immunosuppression, high viral loads in the CSF, prototypic changes on cranial magnetic resonance imaging are associated with HIV-associated dementia and Minor Neurocognitive Disorders but the diagnosis rests on the overall presentation of clinical features together with supporting laboratory evidence.

\section{Differential diagnosis}

The differential diagnoses for HIV-associated Dementia/ Minor Neurocognitive Disorder are broad with an immediate need to exclude other treatable infections that are common in HIV/AIDS patients, including Cryptococcal meningitis, Toxoplasmic encephalitis, Progressive Multifocal Leukoencephalopathy and Cytomegalovirus encephalitis. The combination of neuroimaging and cerebrospinal fluid analyses is usually sufficient to exclude these infections. A history of past or current substance abuse is essential to ascertain, permitting exclusion of delirium or residual neuropsychiatric deficits, especially evident with long-standing crack/cocaine use. A paradoxical deterioration in neurological status following initiation of highly active antiretroviral therapy is termed Neurological Immune Reconstitution Inflammatory Syndrome (NeuroIRIS) and requires exclusion based on history and neuroimaging. Other neurodegenerative disorders including Alzheimer's disease and vascular dementia are becoming more prevalent as the HIV/AIDS population ages. Again, neuropsychological profile coupled with neuroimaging and cerebrospinal fluid analysis will permit detection of these disorders. Finally, given the evolving demographics of HIV infection, especially in North America and Europe, it is essential to evaluate other causes of neurocognitive impairment such as head injury, hepatitis $\mathrm{C}$ virus infection and pre-existing or concurrent neuropsychiatric disorders (schizophrenia, depression, anxiety disorders, sleep disorders).

\section{Treatment}

The most effective therapy for HIV-associated dementia is treatment of the underlying HIV infection with highly active antiretroviral therapy. Highly active antiretroviral therapy usually consists of two nucleoside analogue reverse transcriptase inhibitors and either a ritonavir-boosted protease inhibitor or a non-nucleoside analogue reverse transcriptase inhibitor. Neuropsychological performance shows improvement in HIV/AIDS patients treated with either two nucleoside analogue reverse transcriptase inhibitors and the non-nucleoside analogue reverse transcriptase inhibitor, nevirapine ${ }^{47}$, or with two nucleoside analogue reverse transcriptase inhibitors and a protease inhibitor $^{48,49}$. Specific antiretroviral drugs have higher central nervous system penetration than others, including zidovudine (nucleoside analogue reverse transcriptase inhibitor), stavudine (d4T) (nucleoside analogue reverse transcriptase inhibitor), abacavir (nucleoside analogue reverse transcriptase inhibitor), efavirenz (non-nucleoside analogue reverse transcriptase inhibitor), and indinavir (protease inhibitor) $)^{50,51}$. Highly active antiretroviral therapy shows some benefit in reversing progressive $\mathrm{HIV}$-associated dementia although poor drug penetrance into the central nervous system still limits highly active antiretroviral therapy's efficacy ${ }^{52}$, and thus, other agents have been investigated for their potential neuroprotective properties. It is clear that highly active antiretroviral therapy will contribute to some improvement of signs and symptoms in HIV- 


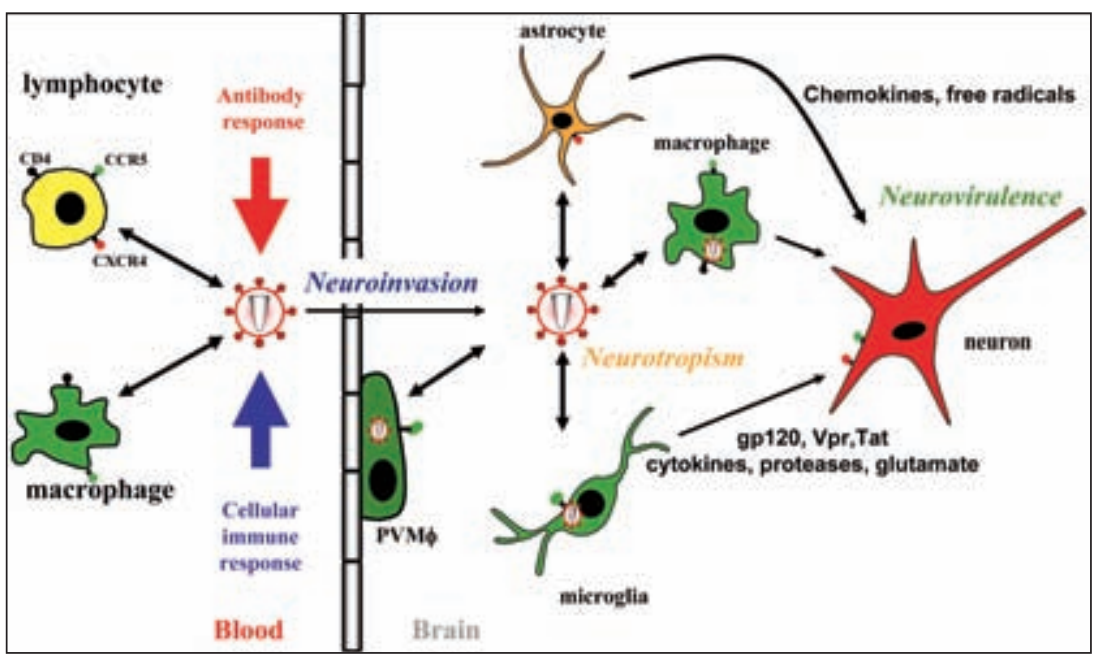

Figure 4: HIV neuropathogenesis in the central nervous system. HIV invades the central and peripheral nervous systems soon after initial infection via infected leukocytes crossing the blood-brain barrier (neuroinvasion). HIV infects resident macrophages, microglia and astrocytes in the central nervous system (neurotropism). Neuronal injury including process retraction and death (apoptosis) results from the release of neurotoxic viral proteins (gp120, $\mathrm{Vpr}$ and Tat) and host molecules (TNF $, I L-1, N O, M M P-2)$ derived from activated or infected glia (neurovirulence) (adapted from ${ }^{16}$ ).

associated dementia/Minor neurocognitive disorder patients who are highly active antiretroviral therapy-naïve but in patients who have been exposed previously to highly active antiretroviral therapy, the benefits of a new antiretroviral drug regimen are less evident ${ }^{53}$. This lack of highly active antiretroviral therapyassociated benefit is most evident for patients who exhibit a plateau or "burned out" phase of HIV-associated dementia ${ }^{54}$. Indeed, some patients receiving highly active antiretroviral therapy show continued neuropsychiatric disease progression despite systemic viral suppression, presumably due to persistent viral replication, neuroimmune activation and ensuing neurodegeneration.

Other neuroprotective strategies for HIV-associated dementia have been investigated ${ }^{1}$. While selegiline was thought initially to exert some neuroprotective effects, a recent randomized controlled trial failed to show any benefit ${ }^{55}$. Although memantine is beneficial in the treatment of Alzheimer's disease and in experimental models of HIV-associated dementia, a recent clinical trial did not show benefits in the primary endpoint, neuropsychological performance, after four months of treatment ${ }^{56}$, which was likely due to the trial being underpowered. Our clinical experience suggests that the closely related drug, amantidine, is also beneficial in HIV-associated dementia patients, especially with marked motor features. The matrix metalloproteinase (MMP) inhibitor, prinomastat ${ }^{57}$ as well as other MMP inhibitors have been shown to block HIV-induced neurotoxicity experimentally and may thus be useful for patients with HIV-associated dementia. Human growth hormone has been shown to be neuroprotective, and may be a component of HIV-associated dementia treatment in the future ${ }^{58}$. Other neurotrophic and neuroprotective factors are currently being developed for the treatment of HIV-associated dementia including minocycline, which suppresses microglia/macrophage activation $^{59}$, as well as valproic acid ${ }^{60}$ with some conflicting data $^{61}$ and newer antiretroviral drugs including viral receptor antagonists and integrase inhibitors.

\section{Neurological Immune Reconstitution Inflammatory Syndrome (NeuroIRIS)}

A subset of highly active antiretroviral therapy-treated patients experience a paradoxical deterioration in their neurological status, usually at the initiation of highly active antiretroviral therapy ${ }^{62}$. This onset of neurological signs and symptoms or worsening of prior neurological disabilities is often apparent in patients with very low $\mathrm{CD}^{+} \mathrm{T}$ cell counts and a concurrent central nervous system opportunistic infection; the clinical worsening occurs as plasma viral suppression begins and has been termed the Neurological Immune Reconstitution Inflammatory Syndrome. NeuroIRIS presents as focal central nervous system deficits including ataxia, hemiparesis and confusion, cerebrospinal fluid pleocytosis and both white matter and cortical abnormalities in neuroimaging (magnetic resonance imaging) and is frequently observed in the context of preexisting Progressive Multifocal Leuko-encephalopathy, Cryptococcal meningitis and occasionally HIV-associated dementia ${ }^{63}$. Neuropathological studies of Neurological Immune Reconstitution Inflammatory Syndrome disclose widespread leukocyte infiltrates in the brain, frequently proximal to the preexisting infection ${ }^{64}$. The extent of neuropsychiatric disability varies widely but may respond to treatment with glucocorticoids but the full impact of Neurological Immune Reconstitution Inflammatory Syndrome in terms of both epidemiology and underlying pathogenesis warrants greater study. 


\section{Other HIV-related CNS disorders (Table 2)}

Other neurological disorders arising due to the direct effects of HIV infection of the CNS include vacuolar myelopathy and seizures. Vacuolar myelopathy is a progressive inflammatory degenerative disorder of the cervical and thoracic spinal cord, resulting in leg weakness and spasticity, increasing sensory loss, bladder dysfunction and occasionally neuropathic pain ${ }^{65}$. Vacuolar myelopathy is clinically evident in approximately 5$10 \%$ of untreated HIV/AIDS patients and usually occurs in very immunosuppressed individuals but has become less prevalent with the advent of highly active antiretroviral therapy; among treated patients, the only signs may be brisk deep tendon reflexes in the legs and mild gait ataxia. Neuropathological studies show intense macrophage activation and infiltration affecting over $50 \%$ of untreated HIV/AIDS patients at autopsy ${ }^{66}$. Vacuolar myelopathy needs to be distinguished for other myelopathies including vitamin B12 deficiency, HTLV-1 myelopathy and varicella zoster virus, syphilitic, tuberculous, or acute transverse myelitis. Neuroimaging (magnetic resonance imaging) and cerebrospinal fluid analysis are often normal in vacuolar myelopathy except for spinal cord atrophy but are essential for excluding other myelopathic conditions. Limited improvement in signs and symptoms associated with vacuolar myelopathy is usually observed with the introduction of highly active antiretroviral therapy, often leaving patients dependent on walking aids, together with medical treatment for a neurogenic bladder and lower limb spasticity.

Seizures are common (5-10\% prevalence) among HIVinfected persons due to opportunistic infections, pre-morbid conditions (head injury) or direct consequences of HIVinfection ${ }^{67}$. Both complex partial and generalized seizures are frequently encountered often concurrent with HIV-associated dementia. Conventional investigations including neuroimaging, electroencephalography and cerebrospinal fluid analysis are necessary to exclude opportunistic infections or other disease processes (malignancy, stroke). While there is a theoretical risk of hepatic interactions between highly active antiretroviral therapy and first-line anticonvulsants (carbamazepine, phenytoin or valproic acid), these potential treatment side effects are rare if anticonvulsant blood levels are closely monitored. The use of gabapentin or levetiracetam as a second drug if the seizure disorder is not controlled by a single anti-convulsant is a comparatively safe option because they are cleared largely through the kidney. The overall prognosis for seizures in the context of HIV infection is good, especially if no focal pathogenic process is identified; patients often return to driving and employment if seizures are the only apparent neurological disorder.

\section{Peripheral nervous system disorders of HIV-1 Infection}

\section{Distal sensory polyneuropathy}

Peripheral neuropathy has become the major neurological complication of HIV infection in the developed world ${ }^{68}$. There are two major neuropathies associated with $\mathrm{HIV}^{69}$, which include the primary HIV-induced neuropathy, distal sensory polyneuropathy and antiretroviral toxic neuropathy, which is caused by antiretroviral drugs such as didanosine (ddI), zalcitabine $(\mathrm{ddC})$, and stavudine $(\mathrm{d} 4 \mathrm{~T})^{65}$, likely due to mitochondrial damage. However, recent studies suggest that protease inhibitors, especially the older protease inhibitors, including indinavir and saquinavir are associated with sensory neuropathy ${ }^{70}$. The prevalence of sensory neuropathy among HIV/AIDS patients in industrialized countries is $30-35 \%$, depending on the diagnostic criteria ${ }^{71}$.

\section{Clinical features}

Both distal sensory and antiretroviral toxic neuropathies are usually defined by neuropathic pain, such as burning or aching sensations in the feet, paresthesiae, allodynia and hyperalgesia, beginning in the toes and soles of the feet that is often worse at night or after walking ${ }^{68}$. These symptoms are often sufficiently severe as to cause or exacerbate mental health issues. In addition, absent or reduced ankle deep tendon reflexes are evident with loss of pinprick, temperature or vibratory sensation (See clinical case). The relative paucity of signs and symptoms in the hands and arms suggests that both neuropathies are length-dependent phenomena. The symptoms and signs of distal sensory polyneuropathy and antiretroviral toxic neuropathy are identical and the two entities are distinguishable only by a history of recent onset neuropathy with initiation of a neurotoxic drug within several months (Table 4).

\section{Diagnosis}

Nerve conduction studies with electromyography are useful for excluding other conditions but may be normal in both distal sensory polyneuropathy and antiretroviral toxic neuropathy, as both syndromes usually involve small diameter fibers and are principally sensory neuropathies ${ }^{72}$. Nerve biopsies are also helpful in eliminating other diagnoses but the recent use of skin (punch) biopsies with analyses of epidermal innervation may be useful for diagnosis in the future ${ }^{73}$. Quantitative sensory testing is not routinely available but is helpful for evaluation of sensory thresholds, which are affected in both distal sensory polyneuropathy and antiretroviral toxic neuropathy. Serum lactate levels are usually not valuable in the diagnosis of antiretroviral toxic neuropathy despite evidence to suggest that mitochondrial dysfunction may contribute to the pathogenesis of antiretroviral toxic neuropathy ${ }^{74}$. It is helpful to document the severity of neuropathic pain at the time of diagnosis and during the course of treatment using established scales including the McGill Pain, Gracely or the Visual Analogue Scales for treatment assessment. It is also imperative to rule out other causes of painful sensory neuropathy such as diabetes, syphilis, nutritional deficiency, ethanol abuse and other neurotoxic drugs (metronidazole, ethambutol, vincristine, taxol, thalidomide and isoniazid) ${ }^{75}$.

\section{Treatment}

DSP usually shows improvement in untreated patients who begin on highly active antiretroviral therapy. It is important to avoid neurotoxic antiretroviral drugs that can exacerbate HIVinduced neuropathy. The treatment of antiretroviral toxic neuropathy necessitates elimination of the neurotoxic agent and implementing an alternative component into the highly active antiretroviral therapy regimen. In effect, the treatment modalities 
Table 1: Definition of acquired immunodeficiency syndrome $(\text { AIDS })^{83}$

AIDS is defined as a CD4+ T lymphocyte count below 200 cells $/ \mu \mathrm{l}$ of blood and/or the presence of an AIDS-defining illness including:

- HIV-associated dementia

- Opportunistic infections such as Pneumocystis jiroveci pneumonia , Kaposi's sarcoma, Mycobacterium avium and tuberculosis, Cryptococcal meningitis, Toxoplasmic encephalitis, Progressive Multifocal Leukoencephalopathy, primary central nervous system lymphoma and cytomegalovirus encephalitis

- HIV wasting syndrome

Table 2: Other primary nervous system syndromes associated with HIV infection

- Central Nervous System:

${ }^{\circ}$ Aseptic Meningitis: presents as part of the constellation of symptoms often associated with primary HIV infection/seroconversion ${ }^{84}$

${ }^{\circ}$ Primary HIV-Induced Headache: non-throbbing headache associated with photophobia with no other cause than HIV-1 infection $^{85}$. Treatment with low dose tricyclic antidepressants can be effective.

- Neuromuscular disorders:

${ }^{\circ}$ Mononeuritis Multiplex: asymmetric sensory and motor dysfunction affecting multiple nerves occurring over weeks is suggestive ${ }^{86}$.

${ }^{\circ}$ Diffuse Infiltrative Lymphocytosis Syndrome: subacute sensorimotor neuropathy with neuropathic pain. Responds to highly active antiretroviral therapy in over $60 \%$ of patients although glucocorticoids may be useful in patients who do not respond to highly active antiretroviral therapy ${ }^{87}$.

${ }^{\circ}$ Guillian-Barré Syndrome: similar to sporadic Guillian-Barré Syndrome, treatment options include plasmapheresis or IVIG. Outcome is good for patients with $\mathrm{CD}^{+} \mathrm{T}$ cell counts above 200 cells/ $\mu \mathrm{l}$, although some residual weakness may linger ${ }^{88}$ but also increases susceptibility to other forms of peripheral neuropathy such as distal sensory polyneuropathy.

${ }^{\circ}$ Motor Neuron Disease Syndrome: a amyotrophic lateral sclerosis-like syndrome rarely occurs in patients with HIV infection but responds to highly active antiretroviral therapy ${ }^{89}$

${ }^{\circ}$ Entrapment/Mono-neuropathies Neuropathies: predominantly carpal tunnel syndrome, meralgia paresthetica and radiculopathies ${ }^{68}$

${ }^{\circ}$ Autonomic neuropathy: present in $12 \%$ of HIV-1 seropositive patients, and is frequently observed in conjunction with distal sensory polyneuropathy with associated postural hypotension, gastroparesis and impotence ${ }^{90,91}$.

${ }^{\circ}$ Myopathies: Proximal muscle weakness with or without myalgias and evidence of polymyositis (elevated creatine kinase or inflammation on biopsy). Other common myopathies are caused by zidovudine or HMG-CoA reductase inhibitors $(\text { statins })^{92}$. for both disorders require the use of a non-neurotoxic highly active antiretroviral therapy regimen. Importantly, zidovudine can cause a myopathy as a toxic side-effect, presenting with proximal muscle weakness and myalgias with occasionally elevated creatine kinase levels but it does not cause a peripheral neuropathy.

Clinical trials show that gabapentin is effective for symptomatic treatment of distal sensory polyneuropathy and antiretroviral toxic neuropathy ${ }^{76}$, likely through its actions on calcium channels. Similarly, pregabalin is a promising therapy for distal sensory polyneuropathy and antiretroviral toxic neuropathy although its mechanism is unknown but is probably similar to gabapentin. We have tended to avoid carbamazepine, lamotrigine and topiramate for control of neuropathic pain because of their potential ability to interact with highly active antiretroviral therapy in terms of hepatic metabolism and other side effects (leucopenia, sedation, or weight loss). While effective in the management of pain associated with non-HIV related peripheral neuropathies, clinical trials demonstrate that amitriptyline is minimally beneficial in the control of pain associated with distal sensory polyneuropathy ${ }^{77}$. A recent open label study indicates that a capsaicin-containing preparation, applied topically may be helpful in controlling neuropathyassociated pain in HIV infection ${ }^{78}$. Opioids are also highly effective in the control of neuropathic pain but raise the potential for drug dependence and may interfere with neurocognitive function in patients already at risk for $\mathrm{HIV}$-associated Neurocognitive Disorder. Long acting opiates including fentanyl, methadone and slow-release morphine limit the problem of psychological dependence but can worsen prior neurocognitive impairment. An open-label study suggested that

Table 3: Clinical features of HIV-associated neurocognitive disorders (HIV-associated dementia and minor neurocognitive disorder ${ }^{93}$

- Neurocognitive dysfunction: Memory impairment, poor concentration, psychomotor slowing.

- Emotional disturbance: Apathy and social withdrawal, which can be mistaken for depression. Also irritability, mental inflexibility, and decreased sex drive.

- Motor abnormalities: Weakness, ataxia, clumsy gait, slowing motor skills, tremor, diffuse increase in tone, hyperreflexia, spasticity, abnormal eye movements and parkinsonism. Frontal release signs and myoclonus in advanced stages of disease.

- Brain atrophy and abnormal subcortical white matter signal on magnetic resonance imaging and computerized tomography scanning.

- Pleocytosis, increased protein and high viral load in cerebrospinal fluid.

- Abnormal neuropsychological testing. 
Table 4: Features of distal sensory polyneuropathy and antiretroviral toxic neuropathy ${ }^{94}$

- Symptoms: symmetric burning or aching sensation, paresthesiae, dysesthesiae. Worsens as the day progresses, especially on the sole and dorsum of the feet, nocturnal awakening due to foot pain, rarely due to hand discomfort.

- Signs: stocking distribution loss of pain and temperature sensation, allodynia, hyperalgesia, diminished or absent distal deep tendon reflexes, atrophic skin changes in the feet and venous pooling.

- Abnormal nerve conduction (sensory) testing and sensory thresholds.

- Nerve and skin biopsies show loss of small diameter myelinated and unmyelinated fibres.

human nerve growth factor may be useful for controlling distal sensory polyneuropathy-related pain symptom ${ }^{79}$ but other neurotrophins may be promising therapies for the future.

\section{Conclusions and Future Perspectives}

Given the rising prevalence of HIV/AIDS in both the industrialized and developing worlds, both established and newly recognized HIV-associated neuropsychiatric syndromes may become increasingly important. One topic of keen interest is the appearance and transmission of drug resistant HIV-1 strains whose associated neurological sequelae have not been welldescribed $^{80}$. Furthermore, the extent to which the central or peripheral nervous systems harbor potentially drug-resistant HIV is unknown. This circumstance might convert the nervous system into a virus reservoir, allowing the virus to seed the entire body unhindered because of the relative safety from the immune system provided by the blood-brain and -nerve barriers ${ }^{81}$. Indeed, the effects of newer antiretroviral drugs including CCR5 antagonists, fusion and integrase inhibitors on the nervous system remain uncertain. Another issue that remains unresolved is whether neurocognitive impairment affects the risk of viral transmission by influencing high risk behaviors. While there is wide experience with the neurological disorders caused by the subtype B of HIV-1, a gap in understanding exists regarding the effects of subtype non-B HIV-1 (or HIV-2) infections on the nervous system. Likewise, concurrent hepatitis $\mathrm{C}$ virus infection has become a rising concern because hepatitis $\mathrm{C}$ virus infects the nervous system and seems to be neuropathogenic ${ }^{82}$. Finally, as life expectancies among HIV/AIDS patients increase with greater survival times, neurological disorders associated with aging are becoming more prevalent. Indeed, the risk of hypertension and diabetes mellitus is increasing among in HIV/AIDS patients, in part due to the metabolic abnormalities (hyperglycemia and hyperlipidemia) associated with different highly active antiretroviral therapy regimens coupled with advancing age. Ongoing clinical vigilance is critical to recognize, treat and manage increasingly common HIVassociated neurological conditions, which have can major a impact on the quality of life, longevity and cost to health care.

\section{Question and Answer Section}

\section{Questions}

1. What are the key clinical features of HIV-associated dementia?

2. Which diagnostic tests are required to establish the diagnosis of HIV-associated dementia?

3. What are the signs and symptoms that accompany HIV-related distal sensory polyneuropathy?

4. Which disorders are important to exclude in diagnosing HIV-related distal sensory polyneuropathy?

5. What is the first line treatment for HIV-related distal sensory polyneuropathy?

\section{Answers}

1. Cognitive impairment (forgetfulness, poor concentration and psychomotor slowing); Motor abnormalities (tremor, ataxia, spasticity); Behavioural changes (agitation, apathy)

2. Neuroimaging (MRI, CT); CSF analysis (exclude opportunistic infections); Neuropsychological testing (bedside and formal tests)

3. Pain (allodynia, hyperalgesia), numbness, paresthesiae; reduced ankle deep tendon reflexes, reduced temperature or vibration sensation

4. Antiretroviral toxic neuropathy (ddC, D4T, ddI); diabetes ; hypothyroidism; syphilis; nutritional deficiency (ethanolrelated), other drugs associated with neuropathy (e.g. metronidazole, ethambutol, vincristin)

5. Gabapentin; long acting opiates

\section{ACKNOWLEDGEMENTS}

The authors thank Drs. Anne Fanning and Joan Sametz for helpful comments and Stephanie Skinner and Leah DeBlock for assistance with manuscript preparation. CP holds a Canada Research Chair in Neurological Infection and Immunity and is an Alberta Heritage Foundation for Medical Research Senior Scholar.

\section{REFERENCES}

1. McArthur JC, Brew BJ, Nath A. Neurological complications of HIV infection. Lancet Neurol. 2005;4(9):543-55.

2. World Health Organization "3 by 5" Progress Report, December 2004. World Health Organization and Joint United Nations Programme on HIV/AIDS; 2004.

3. Yeung H, Krentz HB, Gill MJ, Power C. Neuropsychiatric disorders in HIV infection: impact of diagnosis on economic costs of care. AIDS. 2006 Oct 24;20(16):2005-9.

4. Mamidi A, DeSimone JA, Pomerantz RJ. Central nervous system infections in individuals with HIV-1 infection. J Neurovirol. 2002 Jun;8(3):158-67.

5. Roullet E. Opportunistic infections of the central nervous system during HIV-1 infection (emphasis on cytomegalovirus disease). J Neurol. 1999 Apr;246(4):237-43.

6. Pandya R, Krentz HB, Gill MJ, Power C. HIV-related neurological syndromes reduce health-related quality of life. Can J Neurol Sci. 2005 May;32(2):201-4.

7. Power C, Gill MJ, Johnson RT. The neuropathogenesis of HIV infection: host-virus interaction and the impact of therapy. Can J Neuro Sci. 2002;29(1):19-32.

8. Johnson RT. Viral Infections of the nervous system. 2nd ed. Philadelphia: Lippincott-Raven Publishers; 1998.

9. Antinori A, Arendt G, Becker JT, Brew BJ, Byrd DA, Cherner M, et al. Updated research nosology for HIV-associated neurocognitive disorders. Neurology. 2007 Oct 30;69(18):178999. 
10. Jones G, Power C. Regulation of neural cell survival by HIV-1 infection. Neurobiol Dis. 2006 Jan;21(1):1-17.

11. Navia BA, Cho ES, Petito CK, Price RW. The AIDS dementia complex: II. Neuropathology. Ann Neurol. 1986;19(6): 525-35.

12. Sharer LR. Pathology of HIV-1 infection of the central nervous system. A review. J Neuropathol Exp Neurol. 1992;51(1):3-11.

13. Vinters HV, Anders KH. Neuropathology of AIDS. Boca Raton, Florida: CRC Press, Inc.; 1990.

14. McCarthy BG, Hsieh ST, Stocks A, Hauer P, Macko C, Cornblath $\mathrm{DR}$, et al. Cutaneous innervation in sensory neuropathies: evaluation by skin biopsy. Neurology. 1995;45(10):1848-55.

15. Herrmann DN, Griffin JW, Hauer P, Cornblath DR, McArthur JC. Epidermal nerve fiber density and sural nerve morphometry in peripheral neuropathies. Neurology. 1999;53(8):1634-40.

16. van Marle G, Power C. Human immunodeficiency virus type 1 genetic diversity in the nervous system: evolutionary epiphenomenon or disease determinant? J Neurovirol. 2005; 11(2):107-28.

17. Sacktor N. The epidemiology of human immunodeficiency virusassociated neurological disease in the era of highly active antiretroviral therapy. J Neurovirol. 2002 Dec;8 Suppl 2:115-21.

18. Navia BA, Jordan BD, Price RW. The AIDS dementia complex: I. Clinical features. Ann Neurol. 1986;19(6):517-24.

19. Mirsattari SM, Power C, Nath A. Parkinsonism with HIV infection. Mov Disord. 1998;13(4):684-9.

20. Maher J, Choudhri S, Halliday W, Power C, Nath A. AIDS dementia complex with generalized myoclonus. Mov Disord. 1997;12(4): 593-7.

21. Koutsilieri E, Scheller C, Sopper S, ter Meulen V, Riederer P. Psychiatric complications in human immunodeficiency virus infection. J Neurovirol. 2002 Dec;8 Suppl 2:129-33.

22. Alciati A, Fusi A, D'Arminio Monforte A, Coen M, Ferri A, Mellado C. New-onset delusions and hallucinations in patients infected with HIV. J Psychiatry Neurosci. 2001 May;26(3):22934.

23. Power C, McArthur JC, Johnson RT, Griffin DE, Glass JD, Perryman S, et al. Demented and nondemented patients with AIDS differ in brain-derived human immunodeficiency virus type 1 envelope sequences. J Virol. 1994;68(7): 4643-9.

24. Brew BJ. Evidence for a change in AIDS dementia complex in the era of highly active antiretroviral therapy and the possibility of new forms of AIDS dementia complex. AIDS. 2004 Jan 1;18 Suppl 1:S75-8

25. Ellis RJ, Deutsch R, Heaton RK, Marcotte TD, McCutchan JA, Nelson JA, et al. Neurocognitive impairment is an independent risk factor for death in HIV infection. San Diego HIV Neurobehavioral Research Center Group. Arch Neurol. 1997; 54(4):416-24.

26. A randomized, double-blind, placebo-controlled trial of deprenyl and thioctic acid in human immunodeficiency virus-associated cognitive impairment. Dana Consortium on the Therapy of HIV Dementia and Related Cognitive Disorders [see comments]. Neurology. 1998;50(3):645-51

27. Ellis R, Langford D, Masliah E. HIV and antiretroviral therapy in the brain: neuronal injury and repair. Nat Rev Neurosci. 2007 Jan; $8(1): 33-44$.

28. Heaton RK, Marcotte TD, Mindt MR, Sadek J, Moore DJ, Bentley $\mathrm{H}$, et al. The impact of HIV-associated neuropsychological impairment on everyday functioning. J Int Neuropsychol Soc. 2004 May;10(3):317-31.

29. Heaton RK, Velin RA, McCutchan JA, Gulevich SJ, Atkinson JH, Wallace MR, et al. Neuropsychological impairment in human immunodeficiency virus- infection: implications for employment. HNRC Group. HIV Neurobehavioral Research Center [see comments]. Psychosom Med. 1994;56(1):8-17.

30. McArthur JC, Hoover DR, Bacellar H, Miller EN, Cohen BA, Becker JT, et al. Dementia in AIDS patients: incidence and risk factors. Multicenter AIDS Cohort Study. Neurology. 1993; 43(11):2245-52.

31. Tozzi V, Balestra P, Serraino D, Bellagamba R, Corpolongo A, Piselli $\mathrm{P}$, et al. Neurocognitive impairment and survival in a cohort of HIV-infected patients treated with HAART. AIDS Res Hum Retroviruses. 2005 Aug;21(8):706-13
32. Hinkin $\mathrm{CH}$, Hardy DJ, Mason KI, Castellon SA, Durvasula RS, Lam MN, et al. Medication adherence in HIV-infected adults: effect of patient age, cognitive status, and substance abuse. AIDS. 2004 Jan 1;18 Suppl 1:S19-25.

33. Barclay TR, Hinkin CH, Castellon SA, Mason KI, Reinhard MJ, Marion SD, et al. Age-associated predictors of medication adherence in HIV-positive adults: health beliefs, self-efficacy, and neurocognitive status. Health Psychol. 2007 Jan;26(1):40-9.

34. Simpson DM, Tagliati M. Neurologic manifestations of HIV infection [published erratum appears in Ann Intern Med 1995 Feb 15;122(4):317]. Ann Intern Med. 1994;121(10): 769-85.

35. Dal Pan GJ, McArthur JH, Aylward E, Selnes OA, Nance-Sproson TE, Kumar AJ, et al. Patterns of cerebral atrophy in HIV-1infected individuals: results of a quantitative MRI analysis. Neurology. 1992;42(11):2125-30.

36. McArthur JC, Cohen BA, Farzedegan H, Cornblath DR, Selnes OA, Ostrow D, et al. Cerebrospinal fluid abnormalities in homosexual men with and without neuropsychiatric findings. Ann Neurol. 1988;23 Suppl:S34-7.

37. Sacktor N, Skolasky RL, Ernst T, Mao X, Selnes O, Pomper MG, et al. A multicenter study of two magnetic resonance spectroscopy techniques in individuals with HIV dementia. J Magn Reson Imaging. 2005 Apr;21(4):325-33.

38. Ernst T, Chang L, Arnold S. Increased glial metabolites predict increased working memory network activation in HIV brain injury. Neuroimage. 2003 Aug;19(4):1686-93.

39. Wang GJ, Chang L, Volkow ND, Telang F, Logan J, Ernst T, et al. Decreased brain dopaminergic transporters in HIV-associated dementia patients. Brain. 2004 Nov;127(Pt 11):2452-8.

40. Skinner S, Adewale A, DeBlock L, Gill MJ, Power C. Neurocognitive screening tools in HIV/AIDS: comparative performance among patients exposed to antiretroviral therapy. HIV Medicine. In press 2008.

41. Power C, Selnes OA, Grim JA, McArthur JC. HIV Dementia Scale: a rapid screening test. J Acquir Immune Defic Syndr Hum Retrovirol. 1995;8(3):273-8.

42. Sacktor NC, Wong M, Nakasujja N, Skolasky RL, Selnes OA, Musisi S, et al. The International HIV Dementia Scale: a new rapid screening test for HIV dementia. AIDS. 2005 Sep 2;19(13): 1367-74.

43. Jones BN, Teng EL, Folstein MF, Harrison KS. A new bedside test of cognition for patients with HIV infection. Ann Intern Med. 1993 Nov 15;119(10):1001-4.

44. Berghuis JP, Uldall KK, Lalonde B. Validity of two scales in identifying HIV-associated dementia. J Acquir Immune Defic Syndr. 1999 Jun 1;21(2):134-40.

45. Grassi MP, Perin C, Borella M, Mangoni A. Assessment of cognitive function in asymptomatic HIV-positive subjects. Eur Neurol. 1999;42(4):225-9.

46. Price RW, Brew BJ. The AIDS dementia complex. J Infect Dis. 1988;158(5):1079-83.

47. Price RW, Yiannoutsos T, Clifford DB, Zaborski L, Tselis A, Sidtis JJ, et al. Neurological outcomes in late HIV infection:adverse impact of neurological survival and protection effect of antiretroviral therapy. AIDS. 1999;13:1677-85.

48. Sacktor NC, Lyles RH, Skolasky RL, Anderson DE, McArthur JC, $\mathrm{McF}$ arlane $\mathrm{G}$, et al. Combination antiretroviral therapy improves psychomotor speed performance in HIV-seropositive homosexual men. Multicenter AIDS Cohort Study (MACS). Neurology. 1999;52(8):1640-7.

49. von Giesen HJ, Koller H, Theisen A, Arendt G. Therapeutic effects of nonnucleoside reverse transcriptase inhibitors on the central nervous system in HIV-1-infected patients. J Acquir Immune Defic Syndr. 2002 Apr 1;29(4):363-7.

50. Nath A, Berger J. HIV Dementia. Curr Treat Options Neurol. 2004 Mar;6(2):139-51.

51. Letendre S, Marquie-Beck J, Capparelli E, Best B, Clifford D, Collier AC et al. Validation of the CNS penetration-effectiveness rank for quantifying antiretroviral penetration into the central nervous system. Arch Neurol. 2008 Jan; 65(1):65-70.

52. Langford D, Marquie-Beck J, de Almeida S, Lazzaretto D, Letendre S, Grant I, et al. Relationship of antiretroviral treatment to postmortem brain tissue viral load in human immunodeficiency virus-infected patients. J Neurovirol. 2006 Apr;12 (2):100-7. 
53. Letendre SL, McCutchan JA, Childers ME, Woods SP, Lazzaretto D, Heaton RK, et al. Enhancing antiretroviral therapy for human immunodeficiency virus cognitive disorders. Ann Neurol. 2004; 56(3):416-23

54. Brew BJ, Halman M, Catalan J, Sacktor N, Price RW, Brown S, et al. Factors in AIDS dementia complex trial design: results and lessons from the abacavir trial. PLoS Clin Trials. 2007;2(3):e13.

55. Schifitto G, Zhang J, Evans SR, Sacktor N, Simpson D, Millar LL, et al. A multicenter trial of selegiline transdermal system for HIV-associated cognitive impairment. Neurology. 2007 Sep 25; 69(13): 1314-21.

56. Schifitto G, Navia BA, Yiannoutsos CT, Marra CM, Chang L, Ernst $\mathrm{T}$, et al. Memantine and HIV-associated cognitive impairment: a neuropsychological and proton magnetic resonance spectroscopy study. AIDS. 2007 Sep 12;21(14):1877-86.

57. Zhang K, McQuibban GA, Silva C, Butler GS, Johnston JB, Holden $\mathrm{J}$, et al. HIV-induced metalloproteinase processing of the chemokine stromal cell derived factor-1 causes neurodegeneration. Nat Neurosci. 2003;6(10):1064-71.

58. Silva C, Zhang K, Tsutsui S, Holden JK, Gill MJ, Power C. Growth hormone prevents human immunodeficiency virus-induced neuronal p53 expression. Ann Neurol. 2003;54(5):605-14.

59. Zink MC, Uhrlaub J, DeWitt J, Voelker T, Bullock B, Mankowski J, et al. Neuroprotective and anti-human immunodeficiency virus activity of minocycline. JAMA. 2005;293(16):2003-11.

60. Schifitto G, Peterson DR, Zhong J, Ni H, Cruttenden K, Gaugh M, et al. Valproic acid adjunctive therapy for HIV-associated cognitive impairment: a first report. Neurology. 2006 Mar 28; 66(6):919-21.

61. Cysique LA, Maruff P, Brew BJ. Valproic acid is associated with cognitive decline in HIV-infected individuals: a clinical observational study. BMC Neurol. 2006;6:42.

62. Venkataramana A, Pardo CA, McArthur JC, Kerr DA, Irani DN, Griffin JW, et al. Immune reconstitution inflammatory syndrome in the CNS of HIV-infected patients. Neurology. 2006 Aug 8; 67(3):383-8.

63. McCombe JA, Auer RN, Maingat FG, Houston S, Gill MJ, Power C. Neurological immune reconstitution inflammatory syndrome in HIV/AIDS: outcomes and epidemiology. Neurology. 2009 Mar 3;72(9):835-41

64. Miller RF, Isaacson PG, Hall-Craggs M, Lucas S, Gray F, Scaravilli F, et al. Cerebral CD8+ lymphocytosis in HIV-1 infected patients with immune restoration induced by HAART. Acta Neuropathol (Berl). 2004 Jul;108(1):17-23.

65. Dalakas MC, Cupler EJ. Neuropathies in HIV infection. Baillieres Clin Neurol. 1996;5(1):199-218.

66. Di Rocco A. Diseases of the spinal cord in human immunodeficiency virus infection. Semin Neurol. 1999;19 (2):151-5.

67. Kellinghaus C, Engbring C, Kovac S, Möddel G, Boesebeck F, Fischera $\mathrm{M}$, et al. Frequency of seizures and epilepsy in neurological HIV-infected patients. Seizure. 2008 Jan;17(1): 27-33.

68. Keswani SC, Pardo CA, Cherry CL, Hoke A, McArthur JC. HIVassociated sensory neuropathies. AIDS. 2002;16(16):2105-17

69. Fuller GN, Jacobs JM, Guiloff RJ. Nature and incidence of peripheral nerve syndromes in HIV infection. J Neurol Neurosurg Psychiatry. 1993;56(4):372-81.

70. Pettersen JA, Jones G, Worthington C, Krentz HB, Keppler OT, Hoke A, et al. Sensory neuropathy in human immunodeficiency virus/acquired immunodeficiency syndrome patients: protease inhibitor-mediated neurotoxicity. Ann Neurol. 2006 May;59(5): 816-24.

71. Cornblath DR, Hoke A. Recent advances in HIV neuropathy. Curr Opin Neurol. 2006 Oct;19(5):446-50.

72. Pardo CA, McArthur JC, Griffin JW. HIV neuropathy: insights in the pathology of HIV peripheral nerve disease. J Peripher Nerv Syst. 2001;6(1):21-7.

73. Herrmann DN, McDermott MP, Sowden JE, Henderson D, Messing $\mathrm{S}$, Cruttenden $\mathrm{K}$, et al. Is skin biopsy a predictor of transition to symptomatic HIV neuropathy? A longitudinal study. Neurology. 2006 Mar 28;66(6):857-61
74. Zhu Y, Antony JM, Martinez JA, Glerum DM, Brussee V, Hoke A, et al. Didanosine causes sensory neuropathy in an HIV/AIDS animal model: impaired mitochondrial and neurotrophic factor gene expression. Brain. 2007 Aug;130(Pt 8):2011-23.

75. Mendell JR, Sahenk Z. Clinical practice. Painful sensory neuropathy. N Engl J Med. 2003 Mar 27; 348(13):1243-55.

76. Hahn K, Arendt G, Braun JS, von Giesen HJ, Husstedt IW, Maschke $\mathrm{M}$, et al. A placebo-controlled trial of gabapentin for painful HIV-associated sensory neuropathies. J Neurol. 2004 Oct;251 (10): 1260-6.

77. Kieburtz K, Simpson D, Yiannoutsos C, Max MB, Hall CD, Ellis $\mathrm{RJ}$, et al. A randomized trial of amitriptyline and mexiletine for painful neuropathy in HIV infection. AIDS Clinical Trial Group 242 Protocol Team. Neurology. 1998 Dec;51(6):1682-8.

78. Simpson DM, Estanislao L, Brown SJ, Sampson J. An open-label pilot study of high-concentration capsaicin patch in painful HIV Neuropathy. J Pain Symptom Manage. 2008 Mar;35(3):299-306.

79. Schifitto G, Yiannoutsos C, Simpson DM, Adornato BT, Singer EJ, Hollander $\mathrm{H}$, et al. Long-term treatment with recombinant nerve growth factor for HIV-associated sensory neuropathy. Neurology. 2001 Oct 9;57(7):1313-6.

80. Vendrely A, Bienvenu B, Gasnault J, Thiebault JB, Salmon D, Gray F. Fulminant inflammatory leukoencephalopathy associated with HAART-induced immune restoration in AIDS-related progressive multifocal leukoencephalopathy. Acta Neuropathol (Berl). 2005. Apr; 109(4)449-55.

81. Smit TK, Brew BJ, Tourtellotte W, Morgello S, Gelman BB, Saksena NK. Independent evolution of human immunodeficiency virus (HIV) drug resistance mutations in diverse areas of the brain in HIV-infected patients, with and without dementia, on antiretroviral treatment. J Virol. 2004 Sep;78 (18):10133-48.

82. Letendre S, Paulino AD, Rockenstein E, Adame A, Crews L, Cherner M, et al. Pathogenesis of hepatitis $\mathrm{C}$ virus coinfection in the brains of patients infected with HIV. J Infect Dis. 2007 Aug 1;196(3):361-70.

83. Centers for Disease Control-1993 Revised Classification System for HIV Infection and Expanded Surveillance Case Definition for AIDS Among Adolescents and Adults. MMWR. 1992;41 (RR-17):1-19.

84. Brew BJ. HIV Neurology. Oxford University Press; 2001: p. 49

85. Mirsattari SM, Power C, Nath A. Primary headaches in HIVinfected patients. Headache. 1999 Jan;39(1):3-10.

86. Estanislao LB, Morgello S, Simpson DM. Peripheral neuropathies associated with HIV and hepatitis C co-infection: a review. AIDS. 2005 Oct; 19 Suppl 3:S135-9.

87. Moulignier A, Authier FJ, Baudrimont M, Pialoux G, Belec L, Polivka $M$, et al. Peripheral neuropathy in human immunodeficiency virus-infected patients with the diffuse infiltrative lymphocytosis syndrome. Ann Neurol. 1997 Apr;41 (4):438-45

88. Schleicher GK, Black A, Mochan A, Richards GA. Effect of human immunodeficiency virus on intensive care unit outcome of patients with Guillain-Barre syndrome. Crit Care Med. 2003 Jun; 31(6):1848-50.

89. Verma A, Berger JR. ALS syndrome in patients with HIV-1 infection. J Neurol Sci. 2006 Jan 15;240(1-2):59-64.

90. Evenhouse M, Haas E, Snell E, Visser J, Pawl L, Gonzalez R. Hypotension in infection with the human immunodeficiency virus. Ann Intern Med. 1987 Oct;107(4):598-9.

91. Gluck T, Degenhardt E, Scholmerich J, Lang B, Grossmann J, Straub RH. Autonomic neuropathy in patients with HIV: course, impact of disease stage, and medication. Clin Auton Res. 2000 Feb;10(1):17-22.

92. Verma S, Micsa E, Estanislao L, Simpson D. Neuromuscular complications in HIV. Curr Neurol Neurosci Rep. 2004 Jan;4 (1):62-7.

93. Grant I. Neurocognitive disturbances in HIV. Int Rev Psychiatry. 2008 Feb;20(1):33-47.

94. Price RW. Neurological complications of HIV infection. Lancet. 1996;348(9025):445-52. 